\title{
DESENLAÇANDO FIOS SOBRE A AVALIAÇÃO DA APRENDIZAGEM NA ESCOLA
}

\author{
Elayne Christine Costa da Silva ${ }^{1}$ \\ Fernanda dos Santos da Silva ${ }^{2}$
}

\begin{abstract}
Resumo
Este artigo apresenta abordagens e reflexões acerca da concepção de avaliação da aprendizagem dos atores do processo educacional $\mathrm{O}$ caminhar da avaliação da aprendizagem na escola passa por uma reconstrução coletiva de princípios e objetivos relevantes a formação do individuo. É um caminhar que rompe com o estado de conformismo e comodidade do professor e do aluno, e resgata a família para o processo educacional. A avaliação da aprendizagem e a avaliação para a aprendizagem são antagônicas, complexas e ao mesmo tempo se completam. Analisar esse processo no dia a dia da sala de aula e na escola como um todo é desafiador para todos os envolvidos. O procedimento metodológico utilizados foi o levantamento bibliográfico em livros, revistas e artigos selecionados na internet. Conclui-se que a avaliação da aprendizagem escolar não pode ser entendida como um momento final das atividades mensais, bimestrais ou anuais, mas como parte indissociável do ensinar e do aprender diária.
\end{abstract}

Palavras-Chave: Avaliação. Aprendizagem. Coordenador Pedagógico.

\begin{abstract}
This article presents approaches and reflections about the conception of learning assessment of the actors in the educational process The journey of learning assessment in school goes through a collective reconstruction of principles and objectives relevant to the formation of the individual. It is a journey that breaks with the state of conformity and comfort of the teacher and the student, and rescues the family for the educational process. Learning assessment and assessment for learning are antagonistic, complex and at the same time complete. Analyzing this process on a daily basis in the classroom and at school as a whole is challenging for everyone involved. The methodological procedure used was the bibliographic survey of books, magazines and articles selected on the internet. It is concluded that the evaluation of school learning cannot be understood as an end moment of monthly, bimonthly or annual activities, but as an inseparable part of teaching and daily learning.
\end{abstract}

Keywords: Evaluation. Learning. Pedagogical Coordinator.

\section{Introdução}

No atual panorama sobre o processo de avaliar a aprendizagem dos alunos existe a necessidade em direcionar olhares críticos e reflexivos sob a concepção do

\footnotetext{
${ }^{1}$ Doutoranda em Ciências da Educação pela Faculdade Interamericana de Ciências Sociais - FICS. Mestra em Ciências da Educação pela Faculdade Interamericana de Ciências Sociais - FICS. Especialista em Alfabetização e Letramento pela Faculdade São Luiz. Especialista em Coordenação Pedagógica e Gestão Escolar pela SEGMENTO. Especialista em Psicopedagogia Escolar pela Faculdade Contemporânea. Licenciada em Pedagogia pela Universidade do Estado da Bahia UNEB. Coordenadora Pedagógica na rede municipal de Dias D’Ávila - Bahia. Coordenadora Pedagógica e Vice Gestora da rede municipal de Salvador-Bahia. Email: elayne.costta@gmail.com

2 Doutoranda em Ciências da Educação pela Faculdade Interamericana de Ciências Sociais - FICS. Mestra em Ciências da Educação pela Faculdade Interamericana de Ciências Sociais - FICS. Especialista em Alfabetização e letramento pela Faculdade São Luís. Especialista em Psicopedagogia Clinica e Institucional pela Faculdade Juscelino Kubistchek. Licenciada em Normal Superior pela FTC. Docente da rede municipal de Salvador- Bahia. Email: fernanda.fesantos@gmail.com
} 
que é avaliar. Pode-se salientar que "avaliar é medir o processo ensino/aprendizagem, é oferecer recuperação imediata, é promover cada ser humano, é avaliar junto a cada aluno em seus lentos ou rápidos progressos" (BEVENUTTI, 2002, [s/p]).

A avaliação que importa é aquela feita no processo, acompanhada pelo professor a construção do conhecimento do aluno. Pode-se definir avaliação como um exercício mental que possibilita a análise, o conhecimento, o diagnóstico, a medida ou julgamento de um objeto, que deve ser a realidade daqueles que a fazem, uma vez que:

A avaliação é um processo pelo qual se procura identificar, aferir, investigar e analisar as modificações do comportamento e rendimento do aluno, do educador, do sistema, confirmando se a construção do conhecimento se processou, seja este teórico (mental ou prático) (SANT'ANNA, 1995, p. 31).

A avaliação por ocorrer durante o processo de ensino e aprendizagem possibilitando ao educador perceber como cada educando concebe o seu aprendizado. Permitindo assim, oportunizar ao aluno atividades educativas pertinentes ao seu desenvolvimento escolar, com base nas especificidades inerentes a cada um.

O fazer avaliativo é condicionado pela cultura institucional a maneira de vivenciar não depende do trabalho solitário do professor e suas atividades isoladas, é imprescindível a construção de uma cultura avaliativa que transgrida a concepção autoritária, classificatória, punitiva. A avaliação da aprendizagem na escola pública não acompanha o que diz a Lei de Diretrizes e Bases 9394/96. ao determinar que:

A verificação do conhecimento escolar determina que sejam observados os critérios de avaliação contínua e cumulativa da atuação do educando, com prioridade dos aspectos qualitativos sobre os quantitativos e dos resultados ao longo do período sobre os de eventuais provas finais (BRASIL, 1996, Art. 24).

A avaliação escolar é um processo de coleta e análise de dados, tendo em vista verificarem se os objetivos propostos foram atingidos. Faz-se necessário diferenciar avaliação de nota, a avaliação é um processo que precisa de uma reflexão crítica sobre a prática, verificando avanços e dificuldades e o que fazer para superar (VASCONCELOS, 2006). Esta estruturação perpassa incondicionalmente pelas dimensões curriculares, enfocando o planejamento, os atos de ensinar e aprender, o processo avaliativo e a inserção das tecnologias da informação e comunicação. 


\section{O Ensino e a Avaliação da Aprendizagem}

$O$ ato de ensinar, como transmitir conhecimento e também adquirir conhecimento é uma troca mutua entre educador e educando, a medida que se busca formar cidadão consciente dos seus direitos e deveres, pois:

$\mathrm{O}$ ato de ensinar e o de aprender envolvem certa cumplicidade do professor a partir do planejamento das suas decisões de ensino assumidas; mas tal cumplicidade também se constrói nas interações, através do que é falado, do que é entendido, do que é transmitido e captado pelo olhar, pelo movimento do corpo que acolhe, escuta, observa e busca a compreensão do ponto de vista do aluno (LEITE e TASSONI, 2002, p.137).

$O$ ato de ensinar propõe desafios para o educador que muitas vezes se vê frente a diversas situações as quais o leva a questionar a sua própria pratica pedagógica e dentro disto se insere avaliação que vem a ser o instrumento que tenta analisar o desempenho dos educandos.

A avaliação da aprendizagem não deve ser compreendida pelos agentes educacionais como um simples cumprimento de normas a apenas classificar os alunos como aprovados ou reprovados, tendo que ser vista como um momento no qual professor e alunos tem consciência do status da aprendizagem, adquirindo o sentido de uma avaliação formativa, aquela que:

[...] requer abordar os problemas de aprendizagem, ou seja, de posse dos resultados o professor precisa intervir adequadamente. Porém, se não faz interferências ou se as realiza inadequadamente, muito mais do que julgálo, o importante é ajudá-lo a construir outras possibilidades avaliativas (NASCIMENTO, 2012, p. 106).

Para além de identificar a dimensão da aprendizagem do aluno, o professor, diante de uma concepção formativa, precisa utilizar os dados coletados, a partir dos instrumentos avaliativos, a fim de realizar as condutas necessárias para que haja o avanço da aprendizagem, podendo valer-se de diferentes possibilidades avaliativas que mais se adaptem à sua proposta de trabalho.

Tradicionalmente a avaliação é utilizada em âmbito escolar para classificar os alunos, ou seja, por meio das hierarquias de excelência estes ocupam uma determinada posição perante a um grupo, desconsiderando a qualidade do conteúdo de seus conhecimentos e competências (PERRENOUD, 1999). Infelizmente, mesmo com os diversos avanços que ocorreram e continua acontecendo em diversos aspectos inclusive na educação, com criação de leis, novos olhares sobre educação, entre outros, as notas ainda são utilizadas como imposição de comportamentos no que se reflete à repressão para alguns. 
Essa atribuição de notas muitas vezes é atribuída frente a questões e situações de alunos que não consegue superar dificuldades muitas vezes por ter algum tipo de deficiência de aprendizado o que dificulta o tempo todo a construção do seu aprendizado e os impede de avançar, e a tranquilidade para outros, que em si possui facilidade para assimilar conteúdos, compreender a mensagem que o educador busca passar. A avaliação da aprendizagem na escola tem dois objetivos que são "auxiliar o educando no seu desenvolvimento pessoal, a partir do processo de ensino- aprendizagem, e responder à sociedade pela qualidade do trabalho educativo realizado" (LUCKESI, 2002, p.174).

Percebe-se que avaliação propõe ao educador constante reflexão acerca da sua prática, a medida que este a luz de saberes pedagógicos percebam a sua forma de trabalhar e comunicar-se com seus educandos, que influi muito no processo de ensino e aprendizagem e também, apresentar a sociedade os resultados de tudo aquilo que o mesmo procurou desenvolver com seus educandos e como foi feito.

\section{Avaliação Escolar Como Processo de Construção de Conhecimento}

A avaliação escolar não se resume apenas ao ato de por em pratica através de teste e/ou prova escrita tudo aquilo que o educador trabalhou em sala de aula em termos de conteúdos curriculares obrigatórios, onde os educandos memorizam e transcrevem o que compreendeu. A avaliação escolar vem a ser constantes momentos de construção de conhecimentos essenciais para a vida, para a vivencia em sociedade e que ultrapassam a sala de aula e as instalações físicas do âmbito escolar.

Desta maneira, pode-se perceber que muito se tem escrito e discutido sobre avaliação escolar e esse tem sido um aspecto problemático na prática pedagógica. Para o professor, o grande dilema da avaliação está centrado no aproveitamento escolar, em como decidir se o aluno passa ou não de série, uma decisão que pode influenciar muito na vida do aluno e aumentar não apenas os índices de repetência, mas também os de evasão escolar, pois:

A trajetória das funções da avaliação, ao longo da história, mostra que o processo avaliativo não segue padrões rígidos, sendo determinado por dimensões pedagógicas, históricas, sociais, econômicas e até mesmo políticas, diretamente relacionadas ao contexto em que se insere (BATISTA, GURGEL, SOARES, 2006, p. 3). 
Ainda existem muitos professores que não sabem como avaliar, e a eventual prova acaba se transformando em um processo de cobrança dos conteúdos aprendidos ou decorados pelos alunos, ou ainda em vingança do professor, momento em que esse se delicia ao ver o desespero dos alunos diante das questões, onde influencia muito o desempenho dos alunos. Muitos educadores acabam por misturar situações e levam para o lado pessoal, situações de desentendimento com alguns alunos ao decorrer do ano letivo, e assim, o professor internaliza que o momento da avaliação será a hora de resolver seus 'problemas' com aqueles educandos que ele entende de uma forma ou outra tentaram desestruturar sua aula. Vale salientar que:

Muitos professores se esforçam para executar uma avaliação mais
'inteligente', capaz realmente de ajudar os alunos a progredirem. No
entanto, a maioria dos professores ainda vivencia frequentemente essa
avaliação como um peso, ou como um freio, ou ainda tempo perdido, mais
do que como uma ferramenta eficaz a serviço de uma pedagogia dinâmica
(HADJI, 2001, p. 10).

A avaliação do rendimento do aluno ultimamente se tornou uma preocupação diária dos professores, pois faz parte do trabalho docente verificar e julgar o rendimento dos alunos, avaliando os resultados do ensino, e ainda porque o progresso alcançado pelos alunos reflete a eficácia do ensino. Nesse sentido, o rendimento do aluno reflete o trabalho desenvolvido em classe pelo professor, uma vez que, ao avaliar os alunos, o professor está também avaliando seu próprio trabalho, pois "a avaliação faz parte da rotina escolar e é responsabilidade do professor aperfeiçoar suas técnicas de avaliação" (HAYDT, 1988, p. 7).

$O$ ato de avaliar possui duas principais concepções pedagógicas utilizadas nas escolas de hoje são a tradicional e a construtivista, cujo percebemos constantemente na pratica pedagógica de muitos educadores e que em muitas vezes os mesmos, não possui conhecimento suficiente sore elas. A primeira vem sendo muito criticada por sua excessiva ênfase no ensino dos conteúdos. A segunda ficou conhecida, principalmente, por priorizar o 'fazer' dos alunos. O foco da escola tradicional poderia ser:

Sintetizado da seguinte maneira $A$ aquisição de conteúdos selecionados das diferentes ciências, tendo um critério essencialmente acadêmico, com grande desvinculação das representações já trazidas pelo aluno e de seu contexto social e político (MORAES, 2008, p. 17)

Ao falar no método tradicional de avaliação, se percebe o predomínio e resistência de muitos educadores em aceitar o novo, acompanhar as transformações 
no campo educacional e se permitir a criticas que o levem a melhorar a sua maneira de transmitir conhecimentos com os seus educandos. Pois internalizam que somente avaliações escritas é o melhor caminho e não procuram compreender que a ação de avaliar é um ato contínuo e não se resume apenas a atribuição de notas.

A proposta construtivista busca indicar um caminho alternativo para uma nova relação no ensino, levando a uma aprendizagem eficaz em que os conhecimentos já adquiridos pelo aluno são fundamentais para a aprendizagem de novos, e:

\begin{abstract}
A partir de sua vivência, o aluno constrói uma estrutura cognitiva formada por ideias e concepções ligadas ao senso comum do meio social em que está inserido e elabora representações em função das suas próprias experiências (MORETO, 2008, p. 105).
\end{abstract}

A teoria construtivista procura trabalhar o ato de inclusão do educando no planejamento do educador, já que, considera os conhecimentos prévios de cada um possui o que ocasiona uma complementação do que o educador se organizou, o aprendizado acontece de maneira mais consistente, se tona mais motivador e não somente o educando que adquire novos conhecimentos para a vida, mas também o educador aprende, acumula significativas experiências e o que se reflete na sua prática.

Pois o faz perceber o quanto a interação não somente com os seus educandos, mas com todos vem a ser de extrema importância para a construção contínua do conhecimento e desta maneira, a avaliação acaba por não ser mais vista como algo que amedronta, causa repressão e ao contrario agora, como o método que acrescenta novos aprendizados.

\title{
A Importância da Avaliação no Processo de Ensino Aprendizagem
}

No que se refere a avaliação no contexto escolar, pode-se perceber a sua grande importância para a analise e aprimoramento do processo de ensino e aprendizagem, bem como a necessidade tanto das instituições de ensino como também dos educadores reflitam e revejam seus métodos utilizados para passar conhecimento para os seus educandos.

A avaliação com o mecanismo central que em muitos momentos dá o direcionamento que cada educador deva seguir a partir do desempenho dos seus educandos nas diversas formas que poderá ser utilizado para compreender os resultados obtidos através dos exames realizados. Em sentido amplo: 
Avaliação é um processo abrangente da existência humana que implica uma reflexão crítica sobre a prática, no sentido de captar seus avanços, suas resistências, suas dificuldades e possibilitar uma tomada de decisão sobre o que fazer para superar os obstáculos (VASCONCELOS, 1994, p. 43).

O papel do professor é de suma importância, a medida que tende a enfrentar as dificuldades advindas do sistema de educação vigente, tal como problemas que abrangem o processo de avaliação. Assim, o professor como agente transformador tem o compromisso de ser inovador constantemente verificando se seus alunos estão caminhando rumo ao crescimento e desenvolvimento nos mais diferentes aspectos da vida. Vale salientar que "avaliar é necessário. Ter indicadores que apontem a situação de cada aluno é fundamental, mas o principal objetivo disso é ter como foco a aprendizagem não somente dos alunos, mas também de professores" (BOAS, 2008, p.19), deixando bem claro que a avaliação deve ser realizada com competência e ética.

A existência da avaliação é indispensável enquanto aproximação de ideias articuladas e veiculadas nessa sequência de aprendizagem, ou seja, a avaliação deve ser o momento de investigação e reflexão do professor em relação a sua prática docente. A avaliação da aprendizagem deve ser vista como um mecanismo para que o professor possa detectar as dificuldades dos alunos, bem como verificar quais possibilidades esse aluno apresenta para construir novos conhecimentos e atingir os objetivos propostos pelo professor em sua prática educativa.

A importância da avaliação no processo ensino aprendizagem, levanta uma discussão sobre o que é avaliação, e para que serve a avaliação no sistema de ensino, em face dos grandes desafios e obstáculos que os educadores enfrentam, a avaliação é um dos maiores, não o único. Assim, infelizmente existe outros como o próprio desinteresse do aluno, falta de material pedagógico, indisciplina, fatores estes que contribuem para a má qualidade dos resultados finas do processo ensino aprendizagem. Defende que:

\footnotetext{
O professor não assume absolutamente a responsabilidade em relação ao fracasso do aluno. Em primeiro lugar, porque representaria assumir sua incompetência na organização do trabalho pedagógico, uma apresentação inadequada de estímulos à aprendizagem. Em segundo lugar, porque aquilo que faz geralmente se traduz em resultados positivos. Ou seja, alguns alunos, ou a maioria, aprendem. Se a ação produz modificação de comportamentos em alguns alunos, então o problema está nos alunos e não na ação do professor (HOFFMANN, 1991, p.54).
}

O educador já vem a ser um profissional que se encontra sobrecarregado por diversas tarefas atribuídas a ele, e que precisa dar conta de todas, assim, outras 
questões como as supracitadas acima, demonstram que o mesmo, não poderá ser apontado o tempo todo por questões que levam a permanência do educando no mesmo ano/série, mas que todos precisam contribuir de uma forma ou outra para que o aprendizado aconteça.

É visível que a avaliação tenha um sentido mais amplo e complexo, inclui novos métodos, aprimoramentos e novas práticas pedagógicas que se completam e buscam refletir e corrigir possíveis erros do aproveitamento dos estudos, visando sempre uma melhoria na construção do conhecimento. Inicialmente temos a convicção que o conceito de avaliação não se refere apenas a julgar, quantificar, classificar e dar notas para o nível de aprendizagem do aluno.

É de responsabilidade do educador, verificar e analisar o aproveitamento dos estudos, para que se possa a partir dessa análise transformar essa avaliação em um mecanismo estratégico e contínuo afim de que o aluno tenha a oportunidade de adquirir novos conhecimentos e o professor desenvolver seu trabalho sem a preocupação com notas. Inclusive, há a necessidade também de se repensar sobre o fator psicológico que o momento avaliativo ou a própria avaliação em si causa tanto nos alunos, como nos professores.

Em torno dessas práticas avaliativas há um nível de tensão muito grande, muitos alunos sentem-se como se tivessem sofrido injustiças por estarem nervosos nesse momento e seus pensamentos se direcionam para as notas finais, temerosos com uma possível repetência. Por outro lado estão os professores que ao verificarem, pelas fisionomias dos alunos, durante a avaliação e nas notas apresentadas que seus ensinamentos se traduziram em baixos resultados, um sentimento de incompetência paira no ar, pois:

\begin{abstract}
A avaliação, enquanto relação dialógica vai conceber o conhecimento como apropriação do saber pelo aluno e também pelo professor, como açãoreflexão-ação que se passa na sala de aula em direção a um saber aprimorado, enriquecido, carregado de significados, de compreensão. Dessa forma, a avaliação passa a exigir do professor uma relação epistemológica com o aluno - uma conexão entendida como reflexão aprofundada a respeito das formas como se dá a compreensão do educando sobre o objeto do conhecimento (HOFFMANN, 1994, p. 56).
\end{abstract}

A avaliação para o educador passar ter um maior sentido, a medida que o leva a questionar como a mesma poderá contribuir para o aprendizado do aluno e como a mesma poderá melhorar a sua prática em sala de aula. Desta forma, a avaliação escolar como ferramenta essencial no contexto educacional, é um compromisso social que deve proporcionar aos alunos o acesso aos conhecimentos 
sistematizados e aos bens culturais, mas dependendo da maneira como é utilizada, a avaliação pode se aproximar ou se afastar desses objetivos.

Faz-se necessário distinguir avaliar e examinar, uma vez que o ato de avaliar a aprendizagem implica em acompanhamento e reorientação permanente da aprendizagem. Ela se realiza através de um ato rigoroso e diagnóstico e reorientação da aprendizagem tendo em vista a obtenção dos melhores resultados possíveis, frente aos objetivos que se tenha à frente (LUCKESI, 2001).

A avaliação exige um ritual de procedimentos, que inclui desde o estabelecimento de momentos no tempo, construção, aplicação e contestação dos resultados expressos nos instrumentos; devolução e reorientação das aprendizagens ainda não efetuadas. Para tanto, podemos nos servir de todos os instrumentos técnicos hoje disponíveis, contanto que a leitura e interpretação dos dados sejam feita sob a ótica da avaliação, que é de diagnóstico e não de classificação.

O que, de fato, distingue $o$ ato de examinar e 0 ato de avaliar não são os instrumentos utilizados para a coleta de dados, mas sim o olhar que se tenha sobre os dados obtidos: o exame classifica e seleciona, a avaliação diagnostica e inclui. Desta maneira, mesmo com tantas transformações que ocorreram e continuam acontecendo em diversos meios, inclusive no âmbito educacional, ainda prevalece em nossas escolas a prática do exame escolar ao invés da avaliação da aprendizagem de nossos alunos.

Mas vale salientar que ainda mesmo que a passos lentos, a avaliação está ganhando outro caminho e a maneira qualitativa sendo uma boa alternativa para não somente analisar o educando e o seu aprendizado, mas também para acontecer uma maior aproximação entre ele, o educador e demais pessoas que fazem parte da sua vida escolar, proporcionando assim, uma convivência pacifica entre todos, o respeito predominando e a educação nesta sintonia sendo melhor trabalhada e objetivos sedo alcançados e o significado sendo mais consistente.

\section{O Docente o Discente e a Avaliação do Processo de Ensino Aprendizagem}

Atualmente, o processo de ensino e aprendizagem, consiste nos momentos em que o educador vem a ser o mediador entre o educando e o mundo, não somente para a questão de passar os conteúdos pré-estabelecidos sejam transmitidos, mas também faz com que o educando aprenda a fazer a leitura de 
mundo se perceba como cidadão na sociedade em que s encontra, seja atuante quanto aos seus direitos e deveres e lute em benefícios de melhores condições de vida para todos e diminuindo as desigualdades sociais sempre a través da educação.

Neste contexto, a comunicação direta e saudável entre docente e discente vem a ser de extrema importância, a medida que, através desta a construção do conhecimento e aprendizado se torna mais consistente e avaliação acontece de maneira contínua de forma a não julgar, excluir ou somente pontuar, mas considerar os conhecimentos de mundo o cotidiano de cada um, associar o mesmo a situações que o leve a compreender e perceber a presença de diversos conteúdos no seu dia a dia, e que em alguns momentos passa despercebido.

A avaliação passa por muitos entraves e alguma vez pode acontecer de maneira não muito bem planejada para ser executa e acaba por prejudicar os educandos no momento de fazer a mesma. A avaliação é um dos aspectos mais problemáticos do processo de ensino, porque normalmente utilizada apenas com o sentido de verificação, não apresenta efeitos na dinâmica da ação pedagógica conduzida pelo docente. Faz-se necessário alertar para o real significado da avaliação, pois:

\begin{abstract}
A avaliação atravessa o ato de planejar e de executar; por isso contribui em todo o percurso da ação planificada. [...] A avaliação se faz presente não só na identificação da perspectiva político-social, como também na seleção dos meios alternativos e na execução do projeto, tendo em vista a sua construção. [...] É uma ferramenta necessária ao ser humano de construção dos resultados que planificou produzir [...] Ela faz parte de seu modo (do professor) de agir, e por isso, é necessário que seja usada da melhor forma possível. [...] Defino a avaliação da aprendizagem como um ato amoroso, no sentido de que a avaliação, por si, é um ato acolhedor, integrativo, inclusivo.(LUCKESI, 2002, [s.p.]),
\end{abstract}

Ao se pensar na avaliação da aprendizagem em um projeto educativo, podese expressar que:

O ato de avaliar se faz presente em todos os momentos da vida humana [...] ele também está presente em todos momentos vividos em sala de aula. [ ...] A avaliação efetiva vai ocorrer durante o processo, nas relações dinâmicas de sala de aula, que orientam as tomadas de decisões freqüentes, relacionadas ao tratamento do conteúdo e à melhor forma de compreensão e produção do conhecimento pelo aluno. [...] É nas relações cotidianas entre professor e aluno que vai se dar a aprendizagem (HOFFMANN, 2003, [s.p.])

Desta maneira, podemos perceber a diversidade de opiniões sobre as avaliações que se processam em sala de aula, tanto entre os professores, como entre os alunos, e ainda entre alunos e professores, fica evidente. Assim, nesta 
discussão, o único ponto comum é a visão de que a avaliação dos alunos é uma parte esperada e essencial do processo de educação. Como esta avaliação deve ser realizada é uma questão aberta para debate.

É importante que cada professor procure aprimorar seus meios de avaliação, tentando familiarizar-se com o uso de meios variados de tal modo que possa criar e ajustar procedimentos avaliativos que sejam os mais adequados aos seus objetivos de ensino, à linguagem dos conteúdos tratados e à linguagem de seus alunos, e que possam contribuir não só para situar o grupo de alunos e cada aluno face à sua aprendizagem, mas também para estimular esta aprendizagem. Que a avaliação não seja apenas finalista mas, sim, incluída no processo de ensino e aprendizagem como meio para o autodesenvolvimento, tanto dos alunos em suas aprendizagens, quanto dos professores, como profissionais, em detrimento das suas formas de ensinar.

\section{O Coordenador Pedagógico e os Desafios do Processo da Avaliação da Aprendizagem}

A educação no Brasil caminha a passos lentos, porém, por meio das Leis de Diretrizes e Bases, as reflexões a respeito do processo de ensino e aprendizagem tomaram maior espaço nas discussões das equipes diretivas das escolas. Entendese que o processo de ensino e aprendizagem está relacionado ao processo avaliativo, pois é imprescindível avaliar se o ensino está sendo significativo e se há apropriação do conhecimento. Parte-se do pressuposto que as orientações a respeito do ensino, da aprendizagem, da avaliação, entre outros estejam no documento identitário da escola, o Projeto Político Pedagógico (PPP).

No âmbito educacional, pode citar a presença do coordenador pedagógico, que por sua vez, possui diversas atribuições e dentro desse contexto educacional é fundamental que o mesmo dê o suporte necessário para que o educador desempenhe o seu papel com segurança e significado.

Desta maneira, o mesmo vem a ser o alicerce onde cada educador se apoia seja para buscar sugestões de recursos para aulas mais dinamizadas, seja para orientar naquilo em que ele percebe que o andamento não está muito bem e principalmente para dar embasamento ao educador frente a dificuldades que 0 mesmo venha a ter não somente com conteúdos a ser trabalhados, mas também com a comunicação com os educandos. 
Dentro de tudo isto, o coordenador pedagógico tem um grande desafio juntamente com o corpo docente, que vem a ser o processo de avaliação da aprendizagem, que consiste em buscar meios que possibilitem que esta aconteça de forma contínua, da melhor forma possível e que resulte num trabalho satisfatório para todos: educadores, educandos e o próprio coordenador pedagógico. As contribuições do coordenador pedagógico no âmbito escolar são essenciais na condução dos processos de ensino e aprendizagem.

O coordenador pedagógico como parte diretiva da escola tem um papel primordial no que tange ao processo educacional. Sua função ultrapassa a mera supervisão, chamar atenção dos alunos, cobrar uniformes, ser o tapa buraco da escola, como na falta do diretor, do secretário, do professor, da merendeira. Assim, ainda neste pensamento deturpado sobre o papel da coordenação, na definição negativa do coordenador pedagógico, ou seja, o que a supervisão não é (ou não deveria ser), pois:

Não é fiscal de professor, não é dedo-duro (que entrega os professores para a direção ou mantenedora, não é pombo correio (que leva recado da direção para os professores e dos professores para a direção), não é coringa/tarefeiro/quebra galho/salva-vidas (ajudante de direção, auxiliar de secretaria, enfermeiro, assistente social, etc.), não é tapa buraco (que fica 'toureando'os alunos em sala de aula no caso de falta de professor) (VASCONCELLOS, 2006, p. 86 -87).

O coordenador pedagógico, ainda é erroneamente interpretado por muitos educadores, que não buscam compreender que a presença do mesmo na instituição de ensino é de auxilia-lo para que cada vez mais a sua atuação em sala de aula, vem a crescer, melhorar e os resultados seja cada vez mais significativos e gratificantes.

Muitos educadores ainda resistem e em alguns momentos criam problema desnecessários com o mesmo, por que não aceitam criticas construtivas, pensam que já sabem tudo e não precisa rever suas prática e não buscam ser flexíveis para uma transformação positiva que será benéfica tanto para o educador como para o educando.

Mas, também, tanto isso com educadores como com a comunidade, algumas vezes ocorre devido à falta de organização da própria escola; da falta de conhecimento de alguns coordenadores; o fato de querer arcar todas as situações que a instituição vivencia. Todavia, temos a definição positiva ao que se diz respeito à Coordenação Pedagógica, pois: 
[...] é a articuladora do Projeto Político Pedagógico da instituição no campo pedagógico, organizando a reflexão, a participação e os meios para a concretização do mesmo, de tal forma que a escola possa cumprir sua tarefa de propiciar que todos os alunos aprendam e se desenvolvam como seres humanos plenos, partindo do pressuposto de que todos têm direito e são capazes de aprender (VASCONCELLOS, 2006, p. 87).

O papel fundamental do coordenador é buscar fazer com que o ensino e aprendizado aconteçam da maneira mais plena possível, que os educadores percebam a necessidade de ter alguém que possa orienta-lo para o seu crescimento e desenvolvimento profissional, mas também o coordenador pedagógico precisa ter plena consciência do seu papel na escola e que não pode estabelecer normas e regras e que o Projeto Politico Pedagógico é o documento essencial que rege a instituição de ensino e que a comunicação entre todos inclusive a comunidade escolar é fundamental para o bom andamento dos trabalhos a ser realizados na mesma com empenho, profissionalismo e dedicação.

O coordenador pedagógico precisa estabelecer uma parceria entre professores, alunos, pais e direção, garantindo um espaço de troca e diálogo, permitindo que o trabalho aconteça de forma democrática e coerente. Entre as inúmeras funções do coordenador pedagógico na sua rotina escolar, muitas acabam por tirar o foco do seu papel principal minimizando:

Problemas ligados às características de vida do aluno, o seu ambiente familiar, às suas relações com os pais, às suas condições de saúde e nutrição; igualmente aspectos ligados à sua história escolar, seu aproveitamento em outras séries e outras matérias, suas relações com outros professores e com colegas; todos esses aspectos, ligados à vida do discente fora da sala de aula, interferem no seu aproveitamento e, consequentemente no trabalho do professor (FALCÃO, 1994, p. 42)

As funções do coordenador pedagógico vão além das suas atribuições, e que em sua rotina incansável de trabalho muitos não sabem os limites de seu papel, pois aceitam todas as exigências que lhe são impostas, executando tarefas que poderiam ser executadas por outros profissionais assumindo assim uma postura não condizente com o seu papel. Algo que muitas vezes acabam por desviar a sua real função dentro do estabelecimento de ensino.

O coordenador pedagógico é responsável também pelos tipos de avaliação que será feita, de que forma e para que será realizada. Assim, as contribuições deste profissional são inúmeras dentro do âmbito escolar, inclusive no processo da avaliação da aprendizagem. As funções de coordenação pedagógica podem ser sintetizadas nesta formulação: planejar, coordenar, gerir, acompanhar e avaliar todas as atividades pedagógicas didáticas e curriculares da escola e da sala de aula, 
visando atingir níveis satisfatórios de qualidade cognitiva e operativa das aprendizagens dos alunos (LIBANEO, 2015).

Dentro desse contexto, podemos citar as reuniões pedagógicas, que são indispensáveis, por serem momentos de reflexão e maior aproximação entre coordenador e corpo docente, as mesmas precisam ser planejadas e elaboradas pelo coordenador pedagógico, pois é de sua função saber a intenção da reunião, o porquê dela, para quê, qual o objetivo e o que será proposto. Sendo assim uma das atribuições do Coordenador Pedagógico referente à reunião pedagógica é:

Coordenar reuniões pedagógicas e entrevistas com professores, visando
promover a inter-relação horizontal e vertical entre disciplinas, estimular a
realização de projetos conjuntos entre os professores, diagnosticar
problemas de ensino e aprendizagem e adotar medidas pedagógicas
preventivas, adequar conteúdos, metodologias e práticas (Ibid., p. 181),

A coordenação pedagógica tem como principal atribuição a assistência pedagógica didática aos professores, para chegar a uma situação ideal de qualidade de ensino (considerando o ideal e o impossível), auxiliando-os a conceber, construir e administrar situações de aprendizagem adequadas às necessidades educacionais dos alunos, pois: o papel do coordenador pedagógico é de monitoração sistemática da prática pedagógica dos professores, sobretudo mediante procedimentos de reflexão e investigação (lbidem, p. 180).

Para melhor sintetizar o papel do coordenador pedagógico, pode-se analisar a seguinte definição. O Coordenador Pedagógico responde pela viabilização, integração e articulação do trabalho pedagógico-didático em ligação direta com os professores, em função da qualidade do ensino.

Todo o fazer didático e pedagógico da instituição de ensino, cabe ao coordenador pedagógico e principalmente dar diariamente assistência ao educador e viabilizar tudo aquilo que seja necessário e possível para o bom andamento do trabalho de todos e contribuir pra a construção de um ensino de qualidade e sempre ter flexibilidade ao lidar seja com educador, educando, pais e comunidade. O coordenador pedagógico não substitui o papel do professor, e nem deve ser visto como quebra-galho, pombo-correio, bombeiro, sabichão, burocrata ou profeta, mas precisa ter uma visão da vida escolar na sua amplitude ciente de suas responsabilidades junto ao grupo escolar. 


\section{Considerações}

Ao final desta pesquisa pode-se afirmar que a avaliação escolar tem como objetivo comprovar o saber dos alunos, por vezes de modo independente de sua forma de trabalho, e de como se apropriam dos conhecimentos e das novas aprendizagens. Os professores elaboram provas para testar os alunos e não para ajudá-lo em sua aprendizagem e prioriza os exames. Os educandos tornam-se submissos, acostuma-se a aceitar os resultados e cultivam uma personalidade por demais passiva.

A avaliação Escolar é caracterizada por sua pretensa objetividade, por sua padronização, fechada em conteúdos pontuais e fragmentados, centrada em tarefas marcadas pelo isolamento e incerteza a que expõe os alunos, fundada em uma concepção de inteligência, como grandeza e alicerçada sobre a falácia dos prérequisitos do conhecimento encadeado e linear. Faz-se necessário lembrar de que se tem nas mãos um ser humano em formação, com sonhos e desejos que necessitam ser transformado em projetos que possam ser realizados. Certamente não cabe apenas à escola a realização de tais projetos, mas não há dúvidas de que esta pode compartilhar deles, incentivá-los, impedir que desistam de sues sonhos.

Não se consegue mudanças na avaliação enquanto não analisarem as concepções curriculares e a avaliação escolar estiver centrada na busca por um rendimento máximo dos alunos em direção a uma série fixa de objetivos que racionalizam o ensino, dando a impressão de que o saber é fragmentado em compartimentos estanques, e que ano a ano vão constituindo-se em subtotais que devem ser adicionados uns aos outros. Para que mudanças ocorram nesta postura de avaliação deve-se considerar que os alunos aprendem diferentemente porque têm histórias de vida diferentes, são sujeitos históricos e isso condiciona sua relação com o mundo e influencia sua forma de aprender.

Avaliar é buscar informações sobre o aluno, sua vida, sua família, seus sonhos, é conhecer o seu jeito de aprender e saber que existem as mais diferentes formas de avaliação que não se referem somente a aplicação de provas como: produção de projetos, jornais, murais, cartazes, entrevistas, júri simulado, dramatizações, shows, etc.

A avaliação Escolar deve ser concebida como suporte do processo de assimilação dos conteúdos, auxiliando o aprendizado do aluno com a mediação do 
professor. A função da avaliação é de obter informações sobre os avanços e a dificuldade de cada aluno, constituindo-se em um procedimento permanente de suporte ao processo de ensino-aprendizagem, de orientação para o professor planejar ações, a fim de conseguir ajudar o aluno a prosseguir com êxito, seu processo de escolarização. .Cabe ao professor interpretar qualitativamente o conhecimento construído pelo aluno, considerando-se que esse conhecimento abrange as áreas cognitivas, afetivas e sociais.

Para que se possa implantar um processo de avaliação docente com sucesso é preciso realizar uma sensibilização de todos os envolvidos. Deve estar claro para o corpo docente o objetivo da avaliação é a melhoria e não a punição, e, para os alunos a importância de sua opinião (que deve ser a mais justa possível e não um ajuste de contas), para que possam contribuir para a melhoria de sua formação.

O relacionamento entre os professores e alunos deve ser estreitado enquanto parceria gerando uma cumplicidade de ações objetivando um maior aproveitamento. Os professores precisam acompanhar o desenvolvimento das fronteiras tecnológicas para contribuir e interagir com o aluno. Não há como separar avaliação de ensino, não há como pensar avaliação de alunos sem que se tenha claro o papel da educação na vida das pessoas.

O papel do coordenador pedagógico é amplo, exaustivo, mas que exige uma olhar reflexivo, competência e profissionalismo para dar o direcionamento certo aos educadores para que desde o planejamento até a contínua avaliação tudo ocorra conforme o esperado e proponha a satisfação de todos para uma educação de qualidade, profissionais cada vez mais preparados e comunidade participativa com a instituição de ensino.

O coordenador pedagógico deve ser visto como o mediador do professor, o conselheiro referente às questões pedagógicas e o orientador dos processos didáticos. A interação entre o trabalho dos professores e coordenador pedagógico proporciona a formação de cultura voltada para o diálogo, para a participação e para a busca conjunta por soluções que melhorem a prática educativa e a dinâmica do processo avaliativo da aprendizagem. Isso vai gerando um estilo coletivo de perceber as coisas, de pensar os problemas e de encontrar soluções. 


\section{Referências}

BATISTA, H. M. A.; GURGEL, C. R.; SOARES, L. A. A Prática pedagógica da avaliação escolar: um processo em constante construção, 2006

BENVENUTTI, D. B. Avaliação, Sua História e seus Paradigmas Educativos. In: Pedagogia: a Revista do Curso Brasileira de Contabilidade. São Miguel do Oeste SC:, 2002.

BOAS, B. M. F. V. Virando a escola ao avesso por meio da avaliação. Campinas SP: Papirus, 2008.

BRASIL. Lei de Diretrizes e Bases da Educação Nacional, Lei no 9.394, de 24 de dezembro de 1996.

FALCÃO FILHO, J. L. M. Supervisão: Uma análise crítica das críticas.. Belo Horizonte: Coletânea vida na escola: os caminhos e o saber coletivo 1994.

HADJI, C. Avaliação desmistificada. Porto Alegre: Artmed, 2001.

HAYDT, R. C. Avaliação do processo ensino-aprendizagem. São Paulo: Ática, 1988

HOFFMANN, J M.L. Avaliação: mito e desafio-uma perspectiva construtivista. Educação e Realidade, Porto Alegre, 1991.

HOFFMANN, J M.L Avaliação mediadora: uma relação dialógica na construção do conhecimento. Série Idéias. São Paulo: FDE, 1994.

HOFFMANN, J M.L Avaliação mediadora: uma prática em construção da préescola 'a universidade. 20. ed. Porto Alegre: Mediação, 2003.

HOFFMANN, J M.L. Avaliar: respeitar primeiro, educar depois. Porto Alegre, RS: Mediação, 2008.

LEITE, S. A. S. e TASSONI, E.C. M. A afetividade em sala de aula: as condições de ensino e a mediação do professor. In: AZZI, R. G. e SADALLA, A. M. F. de A. (Orgs.) Psicologia e formação docente: desafios e controvérsias. São Paulo, SP: Casa do Psicólogo, 2002

LIBANEO, C. J. Organização e Gestão da escola teoria e prática. São Paulo: Hecus Editora, 2015.

LUCKESI, C. C. Avaliação da aprendizagem: componente do ato pedagógico. São Paulo: Cortez, 2011.

LUCKESI, C. C. Avaliação da aprendizagem escolar: estudos e proposições. São Paulo: Cortez 2002.

MORAES, D. A. Avaliação formativa: ressignificando a prova no quotidiano escolar,: Londrina, PR: Universidade Estadual de Londrina, 2008.

MORETO, V. P. Prova: um momento privilegiado de estudo, não um acerto de contas. 8. ed. Rio de Janeiro: Lamparina, 2008.

NASCIMENTO, M.C.M. Avaliação da aprendizagem: repercussões de modelos pedagógicos nas concepções docentes. Londrina:: Universidade Estadual de Londrina, .2012,

PERRENOUD, P. A avaliação entre duas lógicas. In:

Avaliação: da excelência à regulação das aprendizagens:entre duas lógicas. Porto Alegre: Artes Médicas Sul, 1999.

SANT'ANNA, L. M. Por que avaliar? Como avaliar?: Critérios e instrumentos. 3. Ed. Petrópolis, RJ: Vozes, 1995.

VASCONCELLOS, C.S. Disciplina: construção da disciplina consciente e interativa em sala de aula e na escola. São Paulo: Libertad, 1994

VASCONCELLOS, C.S.. Avaliação concepção dialética: libertadora do processo de avaliação escolar. São Paulo: Libertad, 2006. 